\title{
MAKSIM KESANTUNAN BAHASA MELAYU DIALEK SELIMBAU KABUPATEN KAPUAS HULU
}

\author{
Wiendi Wiranty \\ Program Studi Pendidikan Bahasa dan Sastra Indonesia \\ Fakultas Bahasa dan Seni IKIP PGRI Pontianak \\ ${ }^{1}$ Wiendiwiranty88@gmail.com,
}

\begin{abstract}
Abstrak
Tujuannya adalah mendeskripsikan kesantunan berbahasa melayu dan menjelaskan faktor yang mentukan kesantunan dan ketidaksantunan berbahasa melayu di Kecamatan Selimbau. Penelitian ini menggunakan metode deskriptif yang berbentuk kualitatif. Data dalam penelitian ini berupa tindak tutur yang yang mengandung kesantunan serta penyimpangan dalam berbahasa yang di tuturkan oleh masyarakat Kecamatan Selimbau. Teknik pengumpulan data observasi, komunikasi langsung, dan simak libat cakap. Alat pengumpul data peneliti sendiri sebagai instrument utama. Teknik keabsahan data dalam penelitian ini menggunakan triangulasi sumber. Teknik analisis data menggunakan deskriptif kualitatif menggunakan model analisis interaktif miles dan huberman. Hasil yang diperoleh berdasarkan analisis data dan reduksi data yaitu, ditemukannya pematuhan serta pelanggaran dalam maksim kebijaksanaan pada tuturan masyarakat di Kecamatan Selimbau. Data yang terdapat dalam maksim kedermawanan juga terdapat pelanggar dan pematuhan dalam tuturan masyarakat di Kecamatan Selimbau yang terlihat dari tuturan yang saling menghargai dalam kegiatan bertutur dan berpandang pada prinsip untuk selalu menguntungkan orang lain.
\end{abstract}

Kata kunci : Bahasa, Afiksasi, Bahasa Melayu Dialek Selimbau

\begin{abstract}
The focus in this research is to realize the maxim principle of language politeness in Malay society and to determine the maxim of well mannered and the lack of compensation that is said by the Malay community. There is also a purpose is to describe the politeness of Malay language and explain the factors that mantanan malignant manner and indifference in the District Selimbau. This research uses descriptive method which is qualitative. The data in this research is a speech act which contains the politeness and deviation in the language that is told by the society of Selimbau Sub-district. Observation data collection techniques, direct communication, and refer libat ably. The researcher's own data collection tool as the main instrument. The technique of data validity in this study using source triangulation. Data analysis techniques used descriptive qualitative using interactive analysis model miles and huberman. The results obtained based on data analysis and data reduction that is, the discovery of compliance and violation in the maxim of wisdom in public speech in Selimbau Sub-district. The data contained in the generosity maxim also there are violators and compliance in public speech in Selimbau Subdistrict seen from the speech of mutual appreciation in the activity speak and look on the principle to always benefit others.
\end{abstract}

Keywords: Language, Affixation, Malay dialect Selimbau 


\section{PENDAHULUAN}

Bahasa merupakan sistem lambang bunyi ujaran yang digunakan untuk berkomunikasi oleh masyarakat pemakainya. Bahasa yang baik berkembang berdasarkan suatu sistem, yaitu seperangkat aturan yang dipatuhi oleh pemakainya. Bahasa sendiri berfungsi sebagai sarana komunikasi serta sebagai sarana integrasi dan adaptasi. Bahasa juga merupakan alat komunikasi yang berupa sistem lambang bunyi yang dihasilkan alat ucap manusia. Bahasa terdiri atas kata-kata atau kumpulan kata. Masing-masing mempunyai makna, yaitu, hubungan abstrak antara kata sebagai lambang dengan objek atau konsep yang diwakili kumpulan kata atau kosakata itu oleh ahli bahasa disusun secara alfabetis, atau menurut urutan abjad, disertai penjelasan artinya dan kemudian dibukukan menjadi sebuah kamus.

Dasar dan motif pertumbuhan bahasa itu dalam garis besarnya berupa: (a) untuk menyatakan ekspresi; (b) sebagai alat komunikasi; (c) sebagai alat untuk mengadakan integrasi dan adaptasi sosial; (d) sebagai alat untuk mengadakan kontrol sosial (Keraf, 2001:3). Bahasa sebagai alat untuk eskpresi diri dan sebagai alat komunikasi adalah fungsi bahasa secara sempit. Secara luas, fungsi bahasa adalah untuk mengadakan integrasi dan adaptasi sosial, dan untuk mengadakan kontrol sosial.Bahasa sebagai alat komunikasi yang sangat penting dalam kehidupan karena dengan bahasa manusia dapat berbicara mengenai apapun, baik yang disenangi maupun yang tidak disenangi. Bahasa digunakan untuk menimbulkan suasana gembira, jenuh, marah, dan sebagainya (Soenardji, 2000:5). Aktivitas manusia tidak dapat berlangsung tanpa bahasa. Pada era sekarang ini, semakin tinggi peradaban manusia maka semakin tinggi pula intensitas penggunaan bahasa yang didukung kemajuan teknologi.

Bahasa Melayu Dialek Selimbau Kabupaten Kapuas Hulu merupakan satu diantara bahasa daerah yang ada di wilayah Indonesia tepatnya di Provinsi Kalimantan Barat Kabupaten Kapuas Hulu. Bahasa Melayu dialek Selimbau saat ini masih digunakan oleh masyarakat di Kecamatan Selimbau untuk berkomunikasi baik dilingkungan keluarga, masyarakat maupun di sekolah. Bahasa Melayu dialek Selimbau merupakan bahasa daerah yang unik, karena mempunyai ciri khas tersendiri baik dalam penuturannya dan dialeknya. Bahasa Melayu dialek Selimbau 
merupakan budaya yang harus dipertahankan dan dilestarikan oleh masyarakat Kecamatan Selimbau khususnya.

Bahasa melayu Dialek Selimbau (BMDS) dipakai dan ditutur oleh penduduk suku melayu yang terdapat dikecamatan Selimbau terdiri dari empat belas desa di antaranya beberapa desa Gudang Hilir, desa Gudang Hulu, desa Dalam, desa Nibung, desa Piasak, desa Leboyan, desa Engkerengas, desa Tempurau, benuis Gerayau, desa Sekulat, desa Mawan, desa Vega, desa Semalah, dan desa Jongkong Hulu. Seiring perkembangan zaman bahasa melayu Dialek Selimbau (BMDS) yang digunakan oleh penutur pada desa Nibung, Engkerengas, Tempurau, Sekulat, dan Pega sudah mulai tercemar oleh pengaruh dialek luar sehingga peneliti semakin memantapkan diri untuk meneliti relasi makna adjektiva dalam BMDS.

Penelitian ini menggunakan kajian sosiopragmatik sesuai dengan rencana penelitian ini karena akan dilakukan penelitian langsung dari tuturan di lingkungan masyarakat yang akan diteliti oleh peneliti dalam hal ini sangat berpengaruh penting dalam penelitian yang akan dilaksanakan.Kajian sosiopragmatik yaitu sebuah kajian linguistik yang mengkaji mengenai bahasa dari segi sosial atau masyarakat sehingga Berkomunikasi tidak akan pernah lepas dengan adanya pola berbahasa yang diucapkan, baik secara sopan maupun tidak sopan. Seringkali kita mendengar pembicaraan masyarakat di suatu wilayah tertentu yang mengungkapkan kata-kata kurang sopan. Terkadang, hal itu terucap dipicu oleh keinginan untuk menegaskan tuturannya, agar mitra tutur dapat mengerti atau melakukan sesuatu atas tuturannya tersebut. Menurut Tarigan(12:2009) sosiopragmatik merupakan telaah mengenai kondisi-kondisi 'setempat' atau kondisi-kondisi lokal yang lebih khusus mengenai penggunaan bahasa. Menurut Nurjamily (9:2015) sosiopragmatik adalah suatu studi yang mengkaji tentang ujaran yang disesuaikan dengan situasi tertentu dalam suatu lingkungan tertentu

Kesantunan berbicara berhubungan dengan bahasa yang digunakan. Hal yang harus diperhatikan adalah apakah bahasa yang digunakan menyinggung perasaan lawan bicara kita atau tidak. Kesantunan dalam berbahasa merupakan satu di antara kesantunan dalam kehidupan sehari-hari yang harus diperhatikan oleh 
setiap kalangan. Kesantunan berbahasa terlihat dalam tata cara berkomunikasi secara verbal atau tata cara berbahasa. Dalam penelitian ini peneliti menggunakan prinsip kesantunan Leech karena hingga saat ini masih digunakan dan paling lengkap serta relative paling komprehensif menurut Leech (Rahardi, 2005:59) ada enam maksim prinsip kesantunan. Pertama Maksim kebijaksanaan adalah para peserta pertuturan hendaknya berpegang pada prinsip untuk selalu mengurangi keuntangan dirinya sendiri dan memaksimalkan keuntungan pihak lain. Kedua, maksim kedermawanan atau maksim kemurahan hati, para peserta pertuturan diharapkan dapat menghormati orang lain. Ketiga, maksim pujian menjelaskan bahwa orang akan dapat dianggap santun apabila dalam bertutur selalu berusaha memberikan pujian kepada pihak lain. Keempat, maksim kesederhanaan atau kerendahan hati, menegaskan bahwa peserta tutur diharapkan dapat bersikap rendah hati dengan cara mengurangi pujian terhadap dirinya sendiri. Kelima, maksim pemufakatan menekankan agar para peserta tutur dapat saling membina kecocokan atau kemufakatan di dalam bertutur. Keenam, maksim kesimpatisan mengharapkan agar para peserta tutur dapat memaksimalkan sikap simpati antara pihak yang satu dengan pihak yang lainnya.

Menurut Sari (6:2017) Kesan saling menghargai yang ditimbulkan atas dasar keselarasan dan kesiapan dalam melakukan tindakan maupun dalam menyatakan sesuatu dengan ucapan dapat dijumpai pada berbagai komunikasi dan intraksi yang terarah antara penutur dan mitra tutur. Menurut Wahidah dan Wijaya (3:2017) kesantunan merupakan fenomena kultural, sehingga dalam pesantren, guruguru perlu membina dan mendidik para santrinya berbahasa santun, sebab guru mempunyai peran penting dalam memberikan tauladan bagi santrinya, apabila siswa tidak membiasakan berbahasa santun maka tidak mustahil bahasa santun yang sudah adapun bisa hilang dan lahir generasi yang arogan, kasar, dan kering dari nilai-nilai etika dan agama.

Berkomunikasi tidak akan pernah lepas dengan adanya pola berbahasa yang diucapkan, baik secara sopan maupun tidak sopan. Seringkali mendengar pembicaraan masyarakat disuatu wilayah tertentu, yang mengucapkan kata-kata tidak sopan. Terkadang, hal itu terucap karena di picu keinginan untuk menegaskan 
tuturannya, agar mitra tutur dapat mengerti atau melakukan sesuatu atas tuturannya tersebut.

Fenomena kebahasaan ini tentu saja menarik untuk diteliti karena dapat menambah wawasan keilmuan. Maksim kesantunan dalam bahasa Melayu dialek Selimbau belum pernah dilakukan penelitian sehingga layak untuk diangkat dan perdalam untuk diteliti lebih lanjut. Dalam penelitian ini peneliti menentukan lokasi penelitian tepatnya di Kecamatan Selimbau Kabupaten Kapuas Hulu.

Alasan peneliti tertarik untuk mengkaji bahasa Melayu dialek Selimbau didasarkan pada pertimbangan berikut. Pertama, peneliti sebagai keturunan penutur asli bahasa Melayu Dialek Selimbau. Kedua, bahasa Melayu dialek Selimbau banyak digunakan dalam situasi formal maupun nonformal sebagai alat komunikasi antarsesama penutur bahasa Melayu Selimbau. Ketiga, bahasa ragam lisan seperti bahasa Melayu Selimbau mudah sekali berubah karena pengaruh bahasa lain sehingga terkadang bercampur oleh bahasa lain tersebut. Selain itu, penelitian terhadap bahasa Melayu dialek Selimbau menambah ilmu pengetahuan serta menambah penemuan ilmiah tentang ragam bahasa yang terdapat di Indonesia. Peneliti mengambil maksim bahasa di kecamatan Selimbau Kabupaten Kapuas Hulu karena masyarakat banyak menggunakan kata-kata yang santun dan tidak santun kepada lawan bicaranya baik kepada yang seusia maupun yang lebih tua dari si pembicara. Peneliti juga ingin mengetahui sejauh mana pengetahuan masyarakat khususnya di Kecamatan Selimbau tentang bahasa yang mereka gunakan dari nilai kesantunan dan ketidaksantunan dalam berbicara kepada lawan bicaranya.

\section{METODE}

Penelitian ini termasuk ke dalam jenis penelitian kualitatif yang bersifat deskriptif. Penelitian ini mencatat secara teliti semua fenomena kebahasaan yang senyatanya ada, meneliti, dan memeriksa sistem bahasa berdasarkan data yang sebenarnya (Subroto, 2007:8). Metode yang digunakan untuk memberikan gambaran mengenai hasil maksim kesantunan dalam Bahasa Melayu Dialek Selimbau. Menurut Moleong (1991:16) di dalam metode deskriptif data yang dikumpulkan dapat berasal dari catatan-catatan, naskah wawancara, photo, video, tape, dokumen pribadi, memo, atau catatan, dan doumen resmi lainnya. Data dalam 
penelitian ini berupa kata-kata atau tuturan yang mengandung maksim kesantunan yang digunakan oleh masyarakat Melayu Kecamatan Selimbau. Teknik pengumpalan data yang digunakan dalam peneltian ini adalah teknik observasi, simak libat cakap, wawancara, dan teknik catat. alat pengumpul data yang digunakan adalah peneliti sendirisebagai instrumen kunci dalam pengumpulan data. Dalam hal ini, peneliti dibantu oleh alat-alat pengumpul data berupa pertanyaanpertanyaan dan tuturan oleh penutur asli dan kamera foto.Teknik pemeriksaan keabsahan data dalam penelitian ini adalah ketekunan atau keajegan pengamatan serta trianggulasi sumber. Teknik analisis data dalam penelitian ini menggunakan model analisis interaktif Miles dan Huberman.

\section{HASIL DAN PEMBAHASAN}

Data hasil penelitian disajikan pada bagian ini, kemudian dianalisis, dan ditemukan hasil terkait maksim kebijaksanaan, maksim kedermawanan, maksim pujian, maksim kesederhanaan, maksim permufakatan, dan maksim kesimpatian. Penentuan bentuk pematuhan dan pelanggaran prinsip kesantuanan berbahasa, disusun peneliti berdasarkan skala kesantuanan yang dikemukakan oleh Goefrrey Leech.

\section{Maksim Kebijaksanaan}

Bentuk pematuhan dan pelanggaran yang terjadi dalam kegiatan bertutur pada masyarakat di Kecamatan Selimbau di bawah ini terlihat bahwa penutur mempertimbangkan kaidah kerugian dan keuntungan bagi dirinyasendiri dalam bertutur berdasarkan prinsip maksim kebijaksanaan. Berikut adalah data yang mematuhi serta melanggar maksim kebijaksanaan.

\footnotetext{
Siska : "Makan meh bah, kami lagi kenyang! Tedik udah makan.”

("makanlah dulu, tadi kita semua sudah makan").

Putri : " "way deh udah dulu makan upa, nak nyaman meh aku tuk"

(“ternyata sudah makan duluan, saya jadi sungkan ?")

Siska : " "nesik apa, santai magang."

("tidak apa-apa, tenang saja").

Percakapan antara Siska dan Putri terjadi ketika Putri sedang bertamu kerumah Siska dan Siska pun langsung menawarkan Putri untuk makan,
} 
karena Siska baru selesai memasak, pada tuturan yaitu "Makan meh bah, kami lagi kenyang! Tedik udah makan". ("makanlah dulu, tadi kita semua sudah makan"). Tuturan Ipin sudah santun karena telah menjalankan prinsip maksim kebijaksanaan karena telah memberikan keuntungan untuk pihak lain.

Data 2

$$
\begin{aligned}
& \text { Sasa : “ mauk na makan kerupuk basah?Aku ada ngawai } \\
& \text { tedik." } \\
& \text { (“ mau tidak makan kerupuk basah?Saya ada buat”). } \\
& \text { Desi : “way mauk meh, banyak na ngawai ?” } \\
& \text { (mau lah, banyak tidak buatnya ?") }
\end{aligned}
$$

Tindak tutur dilakukan oleh Sasa kepada saudara perempuannya agar segera menikmati hidangan, dan Sasa pun langsung menjamu makanan yang ia buat yaitu kerupuk basah, tuturan Sasa yaitu "mauk na makan kerupuk basah?Aku ada ngawai tedik." ( "mau tidak makan kerupuk basah? Saya ada buat"). Peristiwa tutur terjadi pada siang hari ketika Sasa menawarkan hidangan kepada Desi. Tuturan Sasa telah merealisasikan prinsip kesantunan kebijaksanaan karena telah memberikan keuntungan bagi pihak lain.

\section{Maksim Kedermawanan}

Para peserta tutur dalam kegiatan bertutur menurut prinsip maksim kedermawanan hendaknya mengurangi keuntungan bagi dirinya sendiri dan menambah pengorbanan bagi diri sendiri. Orang yang bertutur sesuai dengan prinsip tersebut maka akan dikata orang yang santun. Yang hendak bertutur di Kecamatan Selimbau Kabupaten Kapuas Hulu. Berikut adalah data yang mematuhi serta melanggar maksim kedermawanan dalam kegiatan bertutur yang tidak sesuai dengan teori Goofrey Leech.

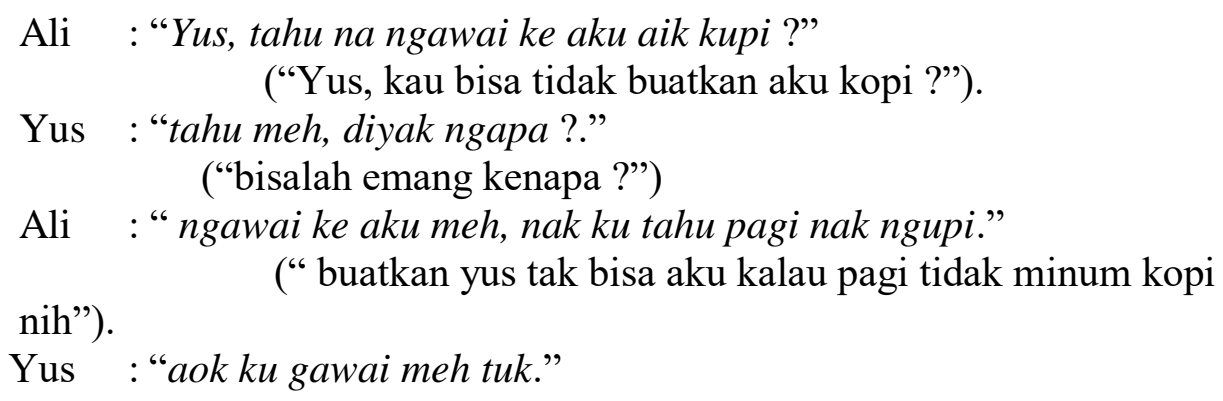


(" iya aku buatkan").

Pembicaraan yang disampaikan Ali di atas terjadi antara buruh kuli bangunan yang sedang bersantai sebelum melakukan pekerjaan, dapat dilihat dengan jelas bahwa ia merugikan pihak lain dengan cara menambah keuntungan untuk dirinya sendiri. Hal itu dilakukan dengan cara menyuruh Yus untuk membuatkan kopi, tampak jelas pada tuturan di atas yaitu "ngawai ke aku meh, nak ku tahu pagi nak ngupi." ( "buatkan yus tak bisa aku kalau pagi tak minum kopi nih").

Jadi maksim yang ada pada percakapan di atas tidak mencerminkan maksim kedermawanan melainkan pelanggaran.

\section{Maksim Penghargaan}

Gagasan dasar maksim penghargaan atau maksim pujian pada prinsip kesantunan adalah bahwa peserta pertuturan hendaknya mengurangi cacian terhadap orang lain dan memaksimalkan pujian bagi orang lain. Orang yang berpegang dan menjalankan prinsip maksim penghargaan ini dianggap sebagai orang yang santun.

\begin{tabular}{|c|c|}
\hline Raudah & $\begin{array}{l}\text { : “bik, baju sepa tuk ?” } \\
\text { (“bik, baju siapa nih ?”) }\end{array}$ \\
\hline Hajijah & $\begin{array}{l}\text { : " baju bibik meh.” } \\
\text { ("baju bibiklah"). }\end{array}$ \\
\hline Raudah & $\begin{array}{l}\text { : "bait baju tuk bik, lembut bahan ya." } \\
\text { (" bagus bajunya bik, lembut bahannya.") }\end{array}$ \\
\hline Hajijah & $\begin{array}{l}\text { : "aok di berik orang baju yak." } \\
\text { (" iya, dikasih tuh"). }\end{array}$ \\
\hline
\end{tabular}

Pembicaraan Raudah dan Hajijah lagi diruang tv, peristiwa tutur terjadi pada saat Raudah sedang menyetrika pakaian yang ada dirumah Hajijah karena Raudah bekerja dirumah Hajijah dan menanyakan pakaian yang ia pegang itu baju siapa, dan Hajijah pun menjawab bahwa pakaian itu punyanya Hajijah, dan Raudahpun memberikan pujian karena pakaian tersebut sangat bagus dan bahannya sangat lembut. Pada tuturan di atas, terindikasi telah merealisasikan prinsip maksim penghargaan karena terdapat tuturan yang mengandung pujian bagi pihak lain. Tuturan itu muncul dari ucapan Raudah yaitu "bait baju tuk bik, 
lembut bahan ya." (“ bagus bajunya bik lembut lagi bahannya”). Jadi, Raudah dapat dikatakan santun karena telah menjalankan prinsip kesantunan berbahasa tepatnya maksim penghargaan.

\section{Maksim Kesederhanaan}

Maksim kesederhanaan memiliki prinsip untuk selalu mengurangi pujian terhadap diri sendiri dan menambah cacian bagi diri sendiri. Penutur yang menerapkan prinsip ini maka akan dikatakan sebagai orang yang santun dalam berbahasa sebaliknya orang yang tidak mematuhi prinsip maksim tersebut maka akan dikatakan sebagai orang yang tidak santun.

Sukron : "adohai, reket aku tuk udah na bait." (“eh raket aku nih sudah jelek").

Sofyan : " "meli raket baru bah." (" beli lagilah raket yang baru").

Sukron : :"na ku mampu meli raket baru."

("tak mampu beli yang baru lagi").

Percakapan di atas terjadi pada sore hari, tampak bahwa Sukron mengurangi pujian terhadap dirinya sendiri dengan tetap merendah menanggapi tuturan Sofyan. Sukron mengaku tidak mampu membeli raket baru, padahal ia sebenarnya sanggup membeli raket baru lagi.

Berdasarkan prinsip kesantunan, Sukron dinyatakan telah merealisasikan maksim kesederhanaan dan dikategorikan sebagai orang yang santun dalam bertutur. Tuturan Sukron yang sesuai dengan maksim kesederhanaan yaitu " $n a k u$ mampu meli raket baru."

\section{SIMPULAN}

Berdasarkan fokus penelitian dan hasil analisis data, maka simpulan penelitian ini sebagai berikut. 1) Penggunaan maksim kebijaksanaan ditemukan bentuk pematuhan dan pelanggaran. Dalam kegiatan bertutur, penutur memandang kaidah bentuk keuntungan dan kerugian serta pilihan yang menghendaki dapat saling menghargai dalam kegiatan bertutur. 2) Data dalam maksim kedermawanan juga terdapat bentuk pematuhan dan pelanggaran, dimana para peserta tutur memandang kaidah saling menghargai dan mempertimbangkan keuntungan dan kerugian bagi diri sendiri dan orang lain serta kaidah pilihan yang membuat tuturan 
semakin santun. Sedangkan bentuk pelanggaran diakibat penutur tidak memandang kaidah keuntungan dan kerugian bagi mitra tutur. 3) Data maksim penghargaan memiliki bentuk pematuhan dan pelanggaran yang didominasi skala formalitas dan kesekawanan serta skala ketidaklangsungan. Bentuk pelanggaran muncul diakibatkan para peserta tutur tidak memperhatikan skala ketidaklangsungan dan mempertimbangkan bentuk pujian terhadap orang lain. 4) Maksim kesederhanaan hanya terdapat bentuk pematuhan yang terindikasi mematuhi kaidah jarak sosial, keotoritasan dan kesekawanan sehingga terjalin rasa saling menghargai dalam kegiatan bertutur.

\section{DAFTAR PUSTAKA}

Hardy, M \& heyes, S. 1998. Pengantar Psikologi. Terjemahan : Soenardji. Jakarta :Erlangga

Keraf, Gorys. (2001). Komposisi. NTT: Nusa Indah.

Leech, G. 1993. Prinsip-prinsip Pragmatik (terjemahan,M.D.D. Oka).Jakarta: UIPress.

Moleong, L.J. 1991. Metodologi Penelitian Kualitatif. Bandung: PT. Remaja Rosdakarya

Nurjamily, Wa Ode. 2015. Kesantunan Berbahasa Indonesia dalam Lingkungan Keluarga (Kajian Sosiopragmatik). Journal Humanika. 9 No.15. vol 3. http://ojs.uho.ac.id/index.php/HUMANIKA/article/view/608/pdf

Rahardi, K. 2005. Pragmatik. Kesantunan Emparatif Bahasa Indonesia. Jakarta: Erlangga

Sari, Ratna.Harum. 2017. Maksim Kesantunan Berbahasa Dalam Wacana Iklan Televisi. Journal Nosi.5.6-7.www.pbindoppsunisma.com/wpcontent/uploads/2017/

Subroto, E. 2007. Pengantar Metode Penelitian Linguistik Struktural. Surakarta: UNS Press.

Tarigan, Henry Guntur. 2009. PengkajianPragmatik. Bandung: Angkasa.

Wahidah, Y.L \& Wijaya, H. 2017. Analisis Kesantunan Berbahasa Menurut Leech Pada Tuturan Berbahasa Arab Guru Pondok Pesantren Ibnul Qoyyim Putra Yogyakarta Tahunajaran 2016/2017 (Kajian Pragmatik). Journal Abayan.9,1,https://media.neliti.com/media/publications/94361-ID-none.pdf 